\title{
Experimental and numerical investigation on forced convection in circular tubes with nanofluids
}

\author{
Laura COLLA ${ }^{1}$, Laura FEDELE $^{1}$, Oronzio MANCA ${ }^{2, *}$, Lorenzo MARINELLI $^{2}$, Sergio NARDINI ${ }^{2}$ \\ *Corresponding author: Tel.: +39 081 5010217; Fax: +39 081 5010204; Email: oronzio.manca@unina2.it \\ ${ }^{1}$ Istituto per le Tecnologie della Costruzione, Consiglio Nazionale delle Ricerche, Corso Stati Uniti 4, 35127 \\ Padova, Italy \\ ${ }^{2}$ Dipartimento di Ingegneria Industriale e dell'Informazione, Seconda Università degli Studi di Napoli, Via \\ Roma 29, 81031 Aversa (CE), Italy
}

\begin{abstract}
In this paper an experimental and numerical study to investigate the convective heat transfer characteristics of fully developed turbulent flow of a water $-\mathrm{Al}_{2} \mathrm{O}_{3}$ nanofluid in a circular tube is presented. The numerical simulations are accomplished on the experimental test section configuration. In the analysis, the fluid flow and the thermal field are assumed axial-symmetric, two-dimensional and steady state. The single-phase model is employed to model the nanofluid mixture and $k-\varepsilon$ model is used to describe the turbulent fluid flow. Experimental and numerical results are carried out for different volumetric flow rates and nanoparticles concentration values. Heat transfer convective coefficients as a function of flow rates and Reynolds numbers are presented. The results indicate that the heat transfer coefficients increase for all nanofluids concentrations compared to pure water at increasing volumetric flow rate. Heat transfer coefficient increases are observed at assigned volumetric flow rate for nanofluid mixture with higher concentrations whereas Nusselt numbers present lower values than the ones for pure water.
\end{abstract}

Keywords: Nanofluids, Forced convection, Tubes, Experimental measurements, Numerical simulations

\section{Introduction}

Several techniques are employed to improve or enhance the heat transfer rate. The heat transfer rate can passively be enhanced by changing flow geometry, boundary conditions or by improving thermophysical properties. In the last years, a strong attention has been addressed toward nanofluids as a possible solution to the problem. A nanofluid is produced by dispersing solid nanoparticles in a base fluid like water, ethylene glycol or oil. Generally, nanoparticles have average size $<100 \mathrm{~nm}$ and can have different sizes and shapes. This type of fluid was called "nanofluid" by Choi (1995). Suspended nanoparticles have higher thermal conductivity than base fluid, thus nanofluids effective thermal conductivity and convective heat transfer coefficient should enhance. Initial studies on the effect of dispersing nanosized particles of $\mathrm{Al}_{2} \mathrm{O}_{3}, \mathrm{SiO}_{2}$ and $\mathrm{TiO}_{2}$ in water are due to Masuda et al. (1993).
Several studies were performed to analyze and verify the advantages of nanofluids in different applications (Cheng, 2009; Taylor et al., 2013) including heat exchangers (Mohammed et al., 2011; Huminic and Huminic, 2012; Hussein et al., 2014). The large application of nanofluids has determined the interest in the numerical simulations and experimental investigations in basic geometrical configuration such as forced convection in circular tubes. Recently, different experimental investigations on nanofluids convection have been performed, in both laminar and turbulent regimes, as reviewed in Terekhov et al. (2010), Sarkar (2011), Chandrasekar et al. (2012) and Hussein et al. (2014).

Investigations on nanofluids convection have been performed in turbulent regimes by Pak and Cho (1998), Xuan and Li (2003), Williams et al. (2008), Duangthongsuk and Wongwises (2009). More recently, Hojjat et al. (2011a, 2011b) carried out experiments on turbulent convection in tubes with three different 
nanoparticles, $\mathrm{Al}_{2} \mathrm{O}_{3}, \mathrm{TiO}_{2}$ and $\mathrm{CuO}$, in an aqueous solution of carboxymethyl cellulose (CMC). Experimental data were compared to heat transfer coefficients, predicted using available correlations for purely viscous nonNewtonian fluids, showing a poor agreement. An empirical correlation was proposed to present the variation of Nusselt number $(\mathrm{Nu})$ with flow and fluid thermophysical parameters. An experimental study was performed to investigate the convective heat transfer characteristics in fully developed turbulent flow of $\mathrm{TiO}_{2}$-water nanofluid by Abbasian Arani and Amani (2013). The results indicated higher $\mathrm{Nu}$ for all nanofluids compared to the base fluids. Generally, $\mathrm{Nu}$ did not increase with the nanoparticles diameter. $\mathrm{Nu}$ and pressure drop were considered to define the thermal performance factor and the results showed that nanofluid with $20 \mathrm{~nm}$ particle size diameter has the highest thermal performance factor in the range of Reynolds number (Re) between 9000 and 49,000 and particle volume concentrations in the range of 0 and 2.0 vol.\%. A turbulent convective heat transfer and pressure drop characteristics of $\mathrm{Al}_{2} \mathrm{O}_{3}$-water nanofluid inside a circular tube were investigated experimentally by Sahin et al. (2013). It was found that the heat transfer increased with the increase of $\mathrm{Re}$ and of volume concentration, with the exception of the particle volume concentrations of 2 and 4 vol.\%. The highest heat transfer enhancement was achieved at $\operatorname{Re}=8000$ and 0.5 vol.\%. Azmi et al. (2013) have experimentally determined the heat transfer coefficients and friction factor with $\mathrm{SiO}_{2}$ /water nanofluid up to $4 \%$ particle volume concentration in a circular tube under constant heat flux boundary condition. The results pointed out that $\mathrm{Nu}$ and friction factor at $3.0 \%$ nanofluid particle concentration were respectively greater than the values of water by $32.7 \%$ and $17.1 \%$. The pressure drop increased with particle concentration up to $3.0 \%$ and decreased thereafter. The heat transfer coefficient decreased when the viscosity to thermal conductivity enhancement ratio was greater than 5.0, as confirmed experimentally with $\mathrm{SiO}_{2}$ nanofluid. Results of heat transfer experimental tests on water-based $\mathrm{TiO}_{2}$ and $\mathrm{SiC}$ nanofluids were reported by Celata et al. (2013). Tests were performed to compare the heat transfer of nanofluids and water at the same velocity or $\mathrm{Re}$, and with values calculated from some of the most widely used correlations. The analysis of the experimental data showed a strong dependence on the parameter used, while both the nanofluid and water data have the same agreement with the calculated values. Their results are in agreement with the observation given by $\mathrm{Yu}$ et al. (2010). Experiments in the fully developed turbulent regime on heat transfer behavior of $\mathrm{MgO}-$ water nanofluid in a circular pipe, for low concentration volume fraction of nanoparticles in the base fluid $(\leq 1 \%)$, were carried out by Hemmat Esfe et al. (2014). The results indicated that adding low amount of nanoparticles to the base fluid gave a remarkable increase of heat transfer. Moreover, the thermal performance factor were greater than unity, indicating that this nanofluid enhanced the heat transfer without huge penalty in pumping power. An experimental investigation on turbulent forced convection in circular tubes with water-based nanofluids containing zinc oxide $(\mathrm{ZnO})$ nanoparticles in concentrations ranging between 1 and $10 \mathrm{wt} \%$ was accomplished by Colla et al. (2014). Experimental and numerical results did not show any increase in the heat transfer coefficient for all the studied suspensions.

As showed in this short review, a lot of investigations have been accomplished on turbulent forced convection in tubes with nanofluids. However, there are many open questions on the use of nanofluids mainly on their convenience also with reference to comparison methods. In the following, an experimental investigation on turbulent forced convection inside a circular tube with nanofluids (water and $\mathrm{Al}_{2} \mathrm{O}_{3}$ nanoparticles) is presented. An assigned heat flux on the external surface of the tube is applied. Results are given in terms of dimensional and dimensionless heat transfer coefficients and performance evaluation coefficient (PEC) for different volumetric concentrations of $\mathrm{Al}_{2} \mathrm{O}_{3}$ 
nanoparticles, $1 \%$ and $3 \%$, and volumetric flow rates with a corresponding Reynolds number from 4100 to 14000 .

\section{Experimental apparatus}

The experimental apparatus is reported in Fig. 1. It consists in a stainless steel circular tube (5), which represents the test section, a peristaltic pump (1), two heat exchanges (9), a tank (4), three ways valves (7), a discharge reservoir (10). Two manometers (6) allow to evaluate the pressure value upstream and downstream the test section. An ultrasonic flow meter (12) is employed to measure the mass flow rate.

The heated part of the test section is $910 \mathrm{~mm}$ long with internal and external diameters equal to $12.66 \mathrm{~mm}$ and $21.55 \mathrm{~mm}$. The length and the diameter of the tube allow in transitionturbulent regime a fully developed flow. The heating was obtained by six electrical resistances, placed on the external surface to have a maximum power of $4200 \mathrm{~W}$. A thermally insulated material, with a thickness of $37 \mathrm{~mm}$, is used to reduce the thermal losses toward the external ambient.

Ten $0.50 \mathrm{~mm}$ outer diameter (OD) ungrounded iron-constantan (J-type) thermocouples are allocated on the external surface to measure the wall temperature along the tube. The thermocouples were placed at the following from the inlet section: $0,10,25,65,145,315$, $485,655,825,1000 \mathrm{~mm}$. The last thermocouple, at $1000 \mathrm{~mm}$, was not taken in consideration in the temperature profiles because it is out from the heated part of the test section. Therefore, it is not considered also in the evaluation of the heat transfer coefficient. One thermocouple is placed inside the inlet section to measure the fluid inlet temperature. An Isotech instrument mod. 938 ice point, with 50 channels and an accuracy of $\pm 0.03{ }^{\circ} \mathrm{C}$, was used as a reference for thermocouple junctions. Their voltages were recorded by an Agilent 34980A data acquisition system. Calibration of the temperature measuring system showed an estimated uncertainty of the thermocouplereadout system of $\pm 0.1{ }^{\circ} \mathrm{C}$. The acquired data were processed and elaborated by an Excel spreadsheet. An ultrasonic system STICK FFU was used to measure the mass flow rate with an accuracy of $\pm 2 \%$.

\section{Preparation of Nanofluid Mixtures}

The mixtures were prepared starting from a suspension of aluminum oxide $\left(\mathrm{Al}_{2} \mathrm{O}_{3}\right)$ in $50 \%$ by mass, dispersed in water. The corresponding volumetric concentration is equal to $20 \%$. The nanofluid was purchased by the company "Alfa Aesar", which has certified and guaranteed nameplate data about the concentrations and average particle size of 43 $\mathrm{nm}$. The nanofluid is stabilized with surfactant additives. A dilution process was employed to obtain the mixture with the desired volumetric concentration adding bi-distillated water to the initial nanofluid mixture. Before the dilution, the initial nanofluid was sonicated by means of the Hielscher mod. UP400S ultrasonic sonicator to ensure the best dispersion of alumina particles in the water. After the dilution process the mixture was again sonicated for 3-4 $\mathrm{h}$ to try to break down possible nanoparticles agglomerations and obtain stable suspensions. The mixtures prepared for the present investigation have volumetric concentration $1 \%$ and $3 \%$. The mixture was immediately charged in the measuring circuit and data acquisition were carried out after about 2-3 h. It was noted that, during experiments, no sedimentation was observed even at low flow rate.

\section{Thermophysical Properties}

The equations for density and specific heat of nanofluid (nf) are given as

$$
\begin{aligned}
\rho_{n f} & =(1-\phi) \rho_{b f}+\phi \rho_{p} \\
C_{n f} & =\frac{(1-\phi) \rho_{b f} C_{b f}+\phi \rho_{p} C_{p}}{(1-\phi) \rho_{b f}+\phi \rho_{p}}
\end{aligned}
$$

The estimation of viscosity $(\mu)$ and thermal conductivity $(k)$ for water based nanofluids was obtained by correlations given in Azmi et al. (2013). The equations are valid for particle concentration lower than $4 \%$, liquid temperature $T_{\mathrm{nf}} \leq 70^{\circ} \mathrm{C}$ and particle diameter 


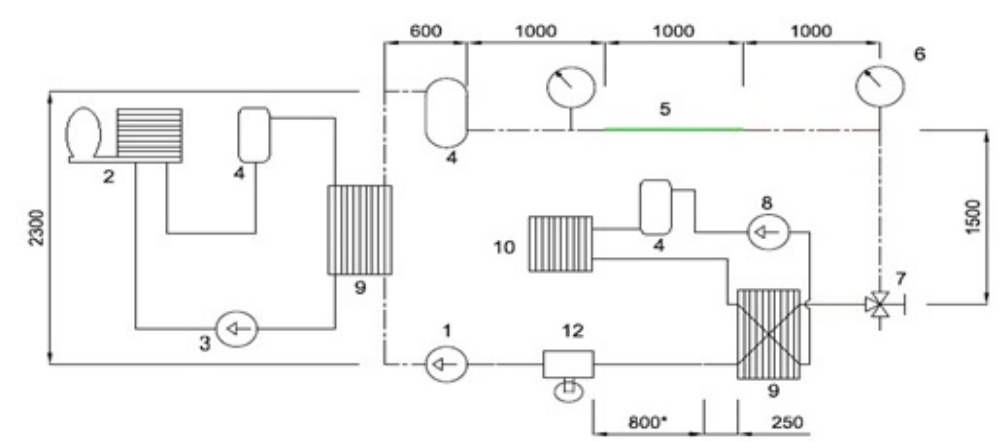

1-Peristaltic pump for nanofluids; 2-Chiller; 3-Centrifugal pump for water chiller circuit; 4-Expension tank; 5-Test section; 6-Manometers; 7-Three ways valve; 8-Centrifugal pump for water-air heat exchanger circuit; 9-Plate heat exchangers; 10-Water-air heat exchanger; 12-Ultrasonic flow meter.

Figure 1 Schematic of the experimental setup

$d_{\mathrm{p}} \leq 170 \mathrm{~nm}$. The equations have the flexibility to estimate the properties of spherical shaped metal and metal oxide nanofluids and water. The values of thermal properties at $20^{\circ} \mathrm{C}$ and $25^{\circ} \mathrm{C}$ are reported in Tables 1 for base fluid, water, nanoparticles material, $\mathrm{Al}_{2} \mathrm{O}_{3}$, and nanofluid at $1 \%$ and $3 \%$. It is worth noting that deviations between calculated and experimental values at $25^{\circ} \mathrm{C}$ are within $1.5 \%$ and $3.9 \%$ for $\lambda$ and $\mu$, respectively.

Table 1 Thermophysical properties of water, $\mathrm{Al}_{2} \mathrm{O}_{3}$ and nanofluids at $20^{\circ} \mathrm{C}$ and $25^{\circ} \mathrm{C}$.

\begin{tabular}{ccccc}
\hline $\begin{array}{c}\mathbf{2 0} \\
{\left[{ }^{\circ} \mathbf{C}\right]}\end{array}$ & $\begin{array}{c}\rho \\
{\left[\mathbf{k g} / \mathbf{m}^{3}\right]}\end{array}$ & $\begin{array}{c}\boldsymbol{c}_{\mathbf{p}} \\
{[\mathbf{J} / \mathbf{k g K}]}\end{array}$ & $\begin{array}{c}\boldsymbol{k} \\
{[\mathbf{W} / \mathbf{m K}]}\end{array}$ & $\begin{array}{c}\boldsymbol{\mu} \\
{[\mathbf{P a ~ s}]}\end{array}$ \\
\hline $\mathrm{H}_{2} \mathrm{O}$ & 998.20 & 4182.20 & 0.599 & 0.001003 \\
\hline $\mathrm{Al}_{2} \mathrm{O}_{3}$ & 3940.00 & 880.00 & 35 & ------- \\
\hline$\phi=1 \%$ & 1027.62 & 4148.62 & 0.619 & 0.001092 \\
\hline$\phi=3 \%$ & 1086.45 & 4082.04 & 0.642 & 0.001363 \\
\hline $\begin{array}{c}\mathbf{2 5} \\
{\left[{ }^{\circ} \mathbf{C}\right]}\end{array}$ & $\begin{array}{c}\rho \\
{\left[\mathbf{k g} / \mathbf{m}^{3}\right]}\end{array}$ & $\begin{array}{c}\boldsymbol{c}_{\mathbf{p}} \\
{[\mathbf{J} / \mathbf{k g K}]}\end{array}$ & $\begin{array}{c}\boldsymbol{k} \\
{[\mathbf{W} / \mathbf{m K}]}\end{array}$ & $\begin{array}{c}\boldsymbol{\mu} \\
{[\mathbf{P a} \mathbf{~ s}]}\end{array}$ \\
\hline $\mathrm{H}_{2} \mathrm{O}$ & 997.00 & 4181.20 & 0.608 & 0.00091 \\
\hline $\mathrm{Al}_{2} \mathrm{O}_{3}$ & 3940.00 & 880.00 & 35 & ----- \\
\hline$\phi=1 \%$ & 1027.42 & 4148.19 & 0.623 & 0.00099 \\
\hline$\phi=3 \%$ & 1086.23 & 4081.56 & 0.645 & 0.00124 \\
\hline
\end{tabular}

\section{Numerical Model and Simulation}

A numerical model was developed based on the test section employed in the experiments, having the geometrical dimensions given in the section 2. In the analysis, the fluid flow and the thermal field were assumed axial- symmetric and the cylindrical coordinates were considered. A two-dimensional and steady state regime were assumed and the single-phase model was employed in order to analyze the thermal and hydrodinamic behavior of the considered nanofluid. In the energy equation, compression work and viscous dissipation were assumed negligible.

To close the governing equations of the thermo-fluidynamic field, experimental data or approximate models were necessary to take into account the turbulence phenomena. In the present work, as suggested by Namburu et al. (2009), the $k-\varepsilon$ model, proposed by Launder and Spalding (1972), was considered. The $k-\varepsilon$ model introduced two new equations, one for the turbulent kinetic energy and the other for the rate of dissipation. In the simulations, the assumed boundary conditions at the channel inlet were uniform profiles for axial velocity, $V_{0}$, and temperature, $T_{0}$. A constant intensity turbulence, equal to $1 \%$, was imposed. At the channel exit section, the fully developed conditions were assumed, i.e. all axial derivatives were zero. On the external wall of the circular tube a uniform heat flux was assigned, the non-slip conditions were assumed on the internal wall. Both turbulent kinetic energy and its dissipation were considered equal to zero. Flow and thermal fields were assumed symmetrical with respect to tube axis. The computational fluid-dynamic code Ansys Fluent (2010) was employed to solve the governing equations, by the control volume method. It was based on the spatial integration of the conservation equations over 
finite control volumes, converting the governing equations to a set of algebraic equations. The algebraic "discretized equations", resulting from this spatial integration process, were sequentially solved throughout the considered physical domain. The residuals resulting from the integration of the governing equations were taken as convergence indicators. Thermophysical properties were evaluated as indicated in the section 4 . Preliminary tests were carried out to check the accuracy of the numerical solution. To this end, three different grids, 16x3600, $24 \times 5000$ and $32 \times 7000$, were compared in terms of Nusselt number. The second grid was employed since it ensured the accuracy of numerical results with a reasonable computational time.

\section{Data reduction}

The heat transfer coefficient evaluated by experimental data is carried out employing the following relations:

$$
h=\frac{Q}{A_{s}\left(T_{s}-T_{b}\right)}
$$

where $A_{s}$ is the heat exchange area, $T_{s}$ is the temperature of the wall, $T_{b}$ the bulk temperature and $Q$ is the electrical energy supplied in the experimental tests, with negligible losses toward the external ambient, or $Q / A_{\mathrm{S}}$ is the assumed wall heat flux in the numerical simulations.

$$
T_{b}=\frac{T_{i}+T_{o}}{2}
$$

where $T_{i}$ and $T_{o}$ are the inlet and outlet temperatures, respectively.

The average Nusselt number is determined with

$$
N u=\frac{h D}{k_{n f}}
$$

where $D$ is the inner tube diameter.

Reynolds number is defined as

$$
R e_{n f}=\frac{\rho_{n f} v D}{\mu_{n f}}
$$

where $v$ is the flow rate and the proprieties are referred to $T_{\mathrm{b}}$.

The uncertainties evaluation is carried out according to the standard single sample analysis recommended by Moffat (1988). The uncertainty values are $8 \%$ and $5 \%$ for the Nusselt and Reynolds numbers, respectively.

\section{Results and Discussion}

Experimental and numerical results were given for assigned wall heat fluxes, referred to the internal surface of the circular tube from about $5400 \mathrm{~W} / \mathrm{m}^{2}$ to about $14000 \mathrm{~W} / \mathrm{m}^{2}$ and a volumetric flow rate in the range from 200 $\mathrm{m}^{3} / \mathrm{h}$ to $520 \mathrm{~m}^{3} / \mathrm{h}$. Reynolds number ranged between 4100 and 14000 and the volumetric concentration of the nanofluids, water- $\mathrm{Al}_{2} \mathrm{O}_{3}$ equal to $0 \%$ (pure water), $1 \%$ and $3 \%$. In the test section, the inlet fluid temperature was controlled by the chiller, during the experimental runs, and set to $20{ }^{\circ} \mathrm{C}$.

In Fig. 2, experimental convective heat transfer coefficients at fixed heat flux $14000 \mathrm{~W} / \mathrm{m}^{2}$, for different concentration, are given as a function of volumetric flow rate in Fig. 2a, and Reynolds number in Fig. 2b, together with the experimental uncertainties. As expected, surface heat transfer increases with flow rate and $\mathrm{Re}$, as well as with volumetric concentration. In both cases, the dependence of this increase seems slight higher at lower volumetric flow rates $(V)$ and Re. At the same Re, nanofluid mixture with higher concentration has higher velocity, corresponding to higher volumetric flow rate, as noted in Fig. 2a. In any case, also for different $\mathrm{Re}$, for assigned volumetric flow rate, the surface heat transfer coefficient is higher at higher concentration. This advantage is lost for the $\mathrm{Nu}$, as reported in Fig. $3 \mathrm{~b}$, due to the higher $k$ at higher concentration. In Fig. 3a, $\mathrm{Nu}$ presents higher values at $\phi=1.0 \%$ for $V=350$ $\mathrm{m}^{3} / \mathrm{h}$ whereas at the highest flow rate $\mathrm{Nu}$ for pure water is the highest. A more direct comparison is accomplished in Fig. 4, where the ratios of $h$ and $\mathrm{Nu}$ of nanofluids and water are shown, as a function of the volumetric flow rate. In all cases (Fig. $4 \mathrm{a}), h_{\mathrm{nf}} / h_{\mathrm{bf}}$ ratios are higher than 1.0 with a maximum increment of $7 \%$ for $V=350 \mathrm{~m}^{3} / \mathrm{h}$. For $\mathrm{Nu}$ ratios (Fig. $5 \mathrm{~b}$ ), for the highest flow rate, the nanofluid mixtures present values lower than 1.0. Considering the 
same rations from numerical simulations, as reported in Fig. 5, $h_{\mathrm{nf}} / h_{\mathrm{bf}}$ (Fig. 5a) decreases with volumetric flow rate increase, being higher than 1.0. In Fig. 5b, $\mathrm{Nu}$ ratio presents values lower than 1.0, for volumetric flow rates higher than $200 \mathrm{~m}^{3} / \mathrm{h}$. This suggests that the use of nanofluid mixtures for high volumetric flow rate could be not advantageous seen by observing $\mathrm{Nu}$ ratio. Moreover, the decrease is greater for higher volumetric concentration.

However, it is interesting to compare directly the heat transfer rate transferred in the tube and the required pumping power in the test section by means of the Performance Evaluation Criteria (PEC), defined as the ratio of heat on the required pumping power in the test section:

$$
P E C=\frac{Q}{V \Delta p}
$$

The values estimated by the experimental data are reported in Fig. 6 as a function of volumetric flow rate. Considering these parameters, the use of nanofluids seem more convenient for higher flow rate. The PEC defined by eq. (7) suggests that there are not increases employing the nanofluids.

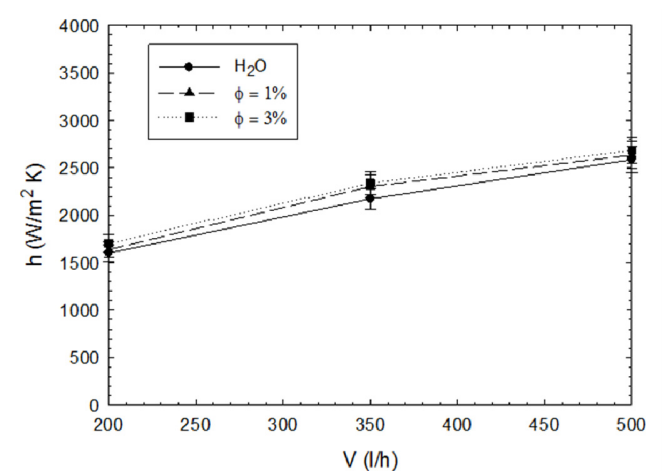

(a)

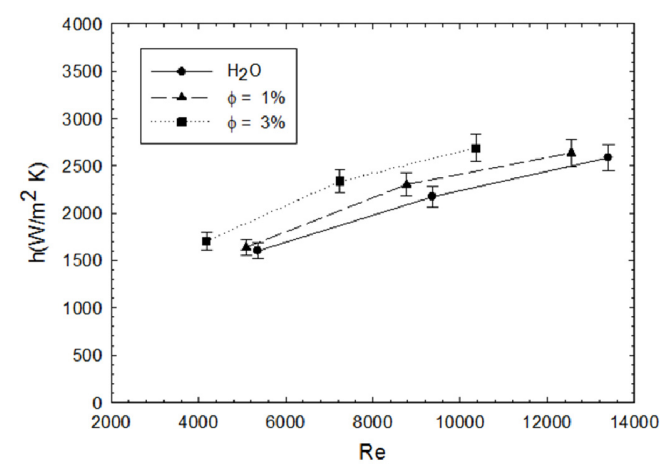

(b)

Figure 2 Experimental convective heat transfer coefficients as a function of: (a) volumetric flow rate, (b) Reynolds number.

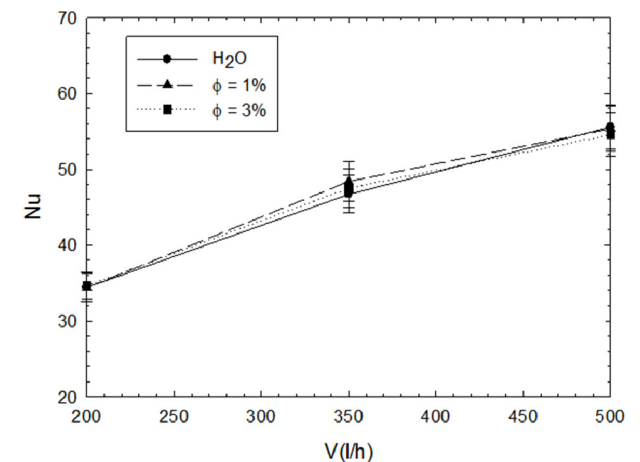

(a)

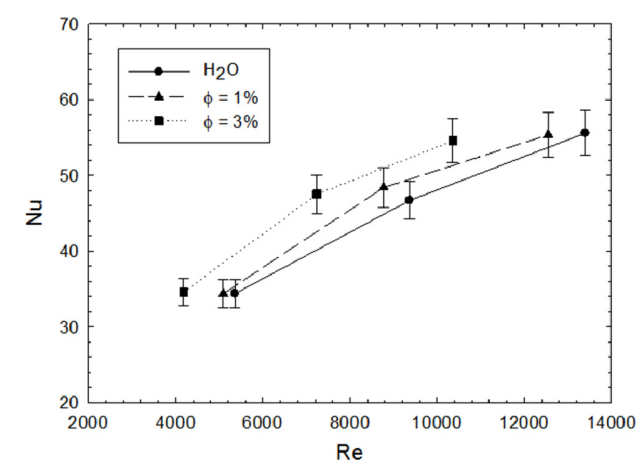

(b)

Figure 3 Experimental Nusselt numbers as a function of: (a) volumetric flow rate, (b) Reynolds number.

\section{Conclusions}

An experimental and numerical investigation on turbulent forced convection flow of a water- $\mathrm{Al}_{2} \mathrm{O}_{3}$ nanofluid in a circular tube was performed. The test section was a circular tube heated at assigned wall heat flux. Results were given in terms of dimensional and dimensionless heat transfer parameters, as a function of volumetric flow rate and Reynolds number for three concentrations. It was observed that the heat transfer coefficients increased rising the volumetric flow rate, for assigned concentration. Some increases of heat transfer coefficient were detected at assigned volumetric flow rate for nanofluid mixture with higher concentrations, whereas in terms of $\mathrm{Nu}$ values the nanofluid mixture presented lower values than the ones for pure water. It should be underlined that other experimental and numerical investigations and tests are necessary to have a clearer understanding of nanofluids thermal behavior also in simple forced convection. 


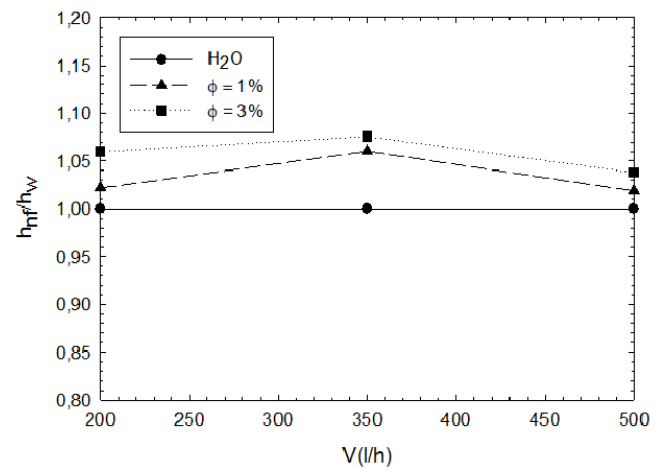

(a)

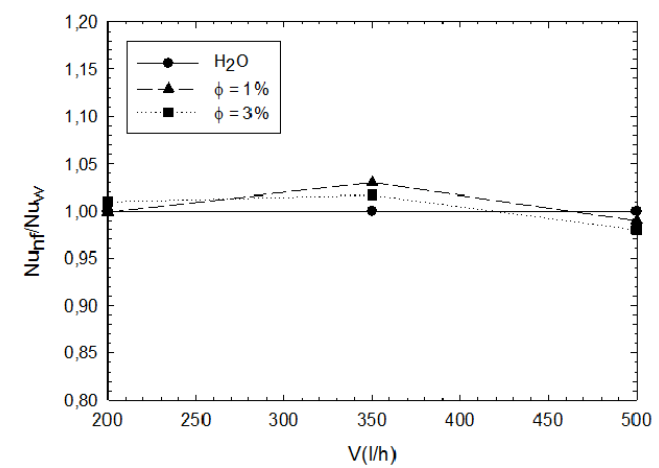

(b)

Figure 4 Experimental (a) convective heat transfer coefficient ratio, (b) Nusselt number ratio between quantities for nanofluid and pure water as a function of volumetric flow rate.

\section{Nomenclature}

$A_{s} \quad$ external area, $\mathrm{m}^{2}$

$c_{p} \quad$ specific heat, $\mathrm{J} \cdot \mathrm{kg}^{-1} \cdot \mathrm{K}^{-1}$

$D \quad$ tube diameter, $\mathrm{m}$

$h \quad$ heat transfer coefficient, $\mathrm{W} \cdot \mathrm{m}^{-2} \cdot \mathrm{K}^{-1}$

$k \quad$ thermal conductivity, $\mathrm{W} \cdot \mathrm{m}^{-1} \mathrm{~K}^{-1}$

$\mathrm{Nu} \quad$ Nusselt number, Eq. (6)

$p \quad$ pressure, $\mathrm{kPa}$

$Q \quad$ wall heat flux, $\mathrm{W} \cdot \mathrm{m}^{-2}$

Re Reynolds number,

$T$ temperature, ${ }^{\circ} \mathrm{C}$

$v \quad$ flow rate, $\mathrm{m} \mathrm{s}^{-1}$

$V \quad$ volumetric flow rate, $\mathrm{m}^{3} \mathrm{~h}^{-1}$

$\phi \quad$ particle volume concentration

Greek letters

$\mu \quad$ dynamic viscosity, $\mathrm{kg} \cdot \mathrm{m}^{-1} \cdot \mathrm{s}^{-1}$

$\rho \quad$ density, $\mathrm{kg} \cdot \mathrm{m}^{-3}$

Subscripts

bf refers to base-fluid

$n f \quad$ refers to nanofluid property

$p \quad$ refers to particle property

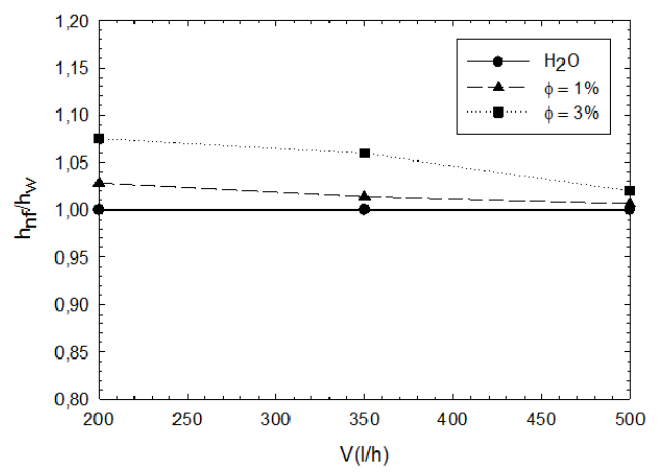

(a)

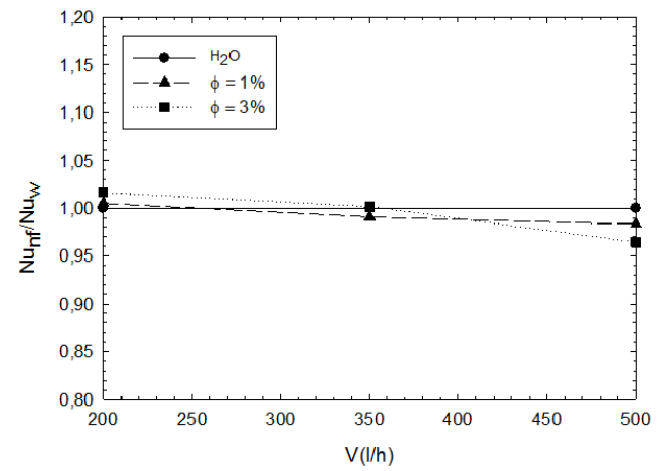

(b)

Figure 5 Calculated (a) convective heat transfer coefficient ratio, (b) Nusselt number ratio between quantities for nanofluid and pure water as a function of volumetric flow rate.

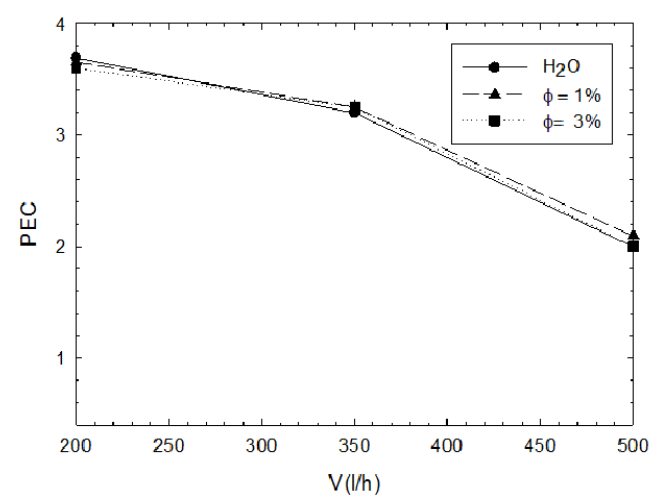

Figure 6 Performance evaluation criteria as a function of volumetric flow rate for differnt concentrations.

\section{References}

Abbasian Arani, A.A., Amani, J., 2013. Experimental investigation of diameter effect on heat transfer performance and pressure drop of $\mathrm{TiO}_{2}$-water nanofluid. Exp. Thermal Fluid Science 44, 520-533.

Azmi, W.H., Sharma, K.V., Sarma, P.K., Mamat, R., Anuar, S., Dharma Rao, V., 2013. Experimental determination of turbulent forced convection heat transfer and friction factor with 
$\mathrm{SiO}_{2}$ nanofluid. Exp. Thermal Fluid Science 51, 103-111.

Ansys Incorporated, 2010. Fluent 14.0 User Manual.

Celata, G. P., D'Annibale, F., Mariani A., Saraceno, L., D'Amato, R., Bubbico, R., 2013. Heat transfer in water-based $\mathrm{SiC}$ and $\mathrm{TiO}_{2}$ Nnanofluids. Heat Transfer Eng. 34, 10601072.

Chandrasekar, M., Suresh, S., Senthilkumar, T., 2012. Mechanisms proposed through experimental investigations on thermophysical properties and forced convective heat transfer characteristics of various nanofluids - A review. Renew. Sust. Energy Rev. 16, 3917-3938.

Cheng, L., 2009. Nanofluid heat transfer technologies, Recent Patents Eng. 3, 1-7.

Choi, S.U.S., 1995. Developments and applications of non-Newtonian flows, ASME FED 66, 99105.

Colla, L., Marinelli, L., Fedele, L., Bobbo, S., Manca, O., 2014. Characterization and simulation of the heat transfer behaviour of water-based $\mathrm{ZnO}$ nanofluids, accepted by $\mathrm{J}$. Nanoscience Nanotech.

Duangthongsuk, W., Wongwises, S., 2009. Heat transfer enhancement and pressure drop characteristics of $\mathrm{TiO}_{2}$-water nanofluid in a double-tube counter flow heat exchanger. Int. J. Heat Mass Transfer 52, 2059-2067.

Hemmat Esfe, M., Saedodin, S., Mahmoodi, M., 2014. Experimental studies on the convective heat transfer performance and thermophysical properties of $\mathrm{MgO}$-water nanofluid under turbulent flow. Exp. Thermal Fluid Science 52, 68-78.

Hojjat, M., Etemad, S.G., Bagheri, R., Thibault, J., 2011a. Turbulent forced convection heat transfer of non-Newtonian nanofluids. Exp. Thermal Fluid Science 35, 1351-1356.

Hojjat, M., Etemad, S.G., Bagheri, R., Thibault, J., 2011b. Convective heat transfer of nonNewtonian nanofluids through a uniformly heated circular tube. Int. J. Thermal Sciences $50,525-531$.

Huminic G., Huminic A., 2012. Application of nanofluids in heat exchangers: A review. Renew. Sust. Energy Rev. 16, 5625-5638.

Hussein, A.M., Sharma, K.V., Bakar, R.A., Kadirgama, K., 2014. A review of forced convection heat transfer enhancement and hydrodynamic characteristics of a nanofluid, Renew. Sust. Energy Rev. 29, 734-743.

Lauder, B. E., Spalding, D. B., 1972. Lectures in Mathematical Models of Turbulence. Academic
Press, London.

Masuda, H., Ebata, A., Teramae, K., Hishinuma, N., 1993. Alteration of thermal conductivity and viscosity of liquid by dispersing ultra fine particles. Netsu Bussei 4, 227-233.

Moffat, R. J., 1988. Describing the uncertainties in experimental results. Exp. Thermal Fluid Science 1, 3-17.

Mohammed, H.A., Bhaskaran, G., Shuaib, N.H., Saidur, R., 2011. Heat transfer and fluid flow characteristics in microchannels heat exchanger using nanofluids: A review, Renew. Sust. Energy Rev. 15, 1502-1512.

Namburu, P. K., Das, D. K., Tanguturi, K. M., Vajjha, R. S., 2009. Numerical study of turbulent flow and heat transfer characteristics of nanofluids considering variable properties. Int. J. Therm. Sci. 48, 290-302.

Pak, B.C., Cho, Y.I., 1998. Hydrody-namic and heat transfer study of dispersed fluids with submicron metallic oxide particles. Exp. Heat Transfer 11, 151-170.

Sahin, B., Gedik Gültekin, G., Manay, E., Karagoz, S., 2013 Experimental investigation of heat transfer and pressure drop characteristics of $\mathrm{Al}_{2} \mathrm{O}_{3}$-water nanofluid. Exp. Thermal Fluid Science 50, 21-28.

Sarkar, J., 2011. A critical review on convective heat transfer correlations of nanofluids. Renew. Sust. Energy Rev. 15, 3271-3277.

Taylor, R., Coulombe, S., Otanicar, T., Phelan, P., Gunawan, A., Lv, W., Rosengarten, G., Prasher, R., Tyagi, H., 2013. Small particles, big impacts: A review of the diverse applications of nanofluids. J. Appl. Physics 113, 011301.

Terekhov, V.I., Kalinina, S.V., Lemanov, V.V., 2010, The mechanism of heat transfer in nanofluids: State of the art (review). Part 2. Convective heat transfer. Thermoph. Aeromechanics 17, 157-171.

Williams, W., Buongiorno, J., Hu, L.W., 2008. Experimental investigation of turbulent convective heat transfer and pressure loss of alumina/water and zirconia/water nanoparticle colloids (nanofluids) in horizontal tubes. J. Heat Transfer 130, 042412.

Xuan Y., Li, Q., 2003. Investigation on convective heat transfer and flow features of nanofluids, ASME J. Heat Transfer 125, 151-155.

$\mathrm{Yu}$, W., France, D. M., Timofeeva, E. V., Singh D., Routbort, J. L., 2010. Thermo-physical property-related comparison criteria for nanofluid heat transfer enhancement in turbulent flow. Appl. Phys. Letters 96, 213109 